\title{
ISSR and AFLP identification and genetic relationships of Chinese elite accessions from the genus Populus
}

\author{
Gao JIANMING ${ }^{\mathrm{a}}$, Zhang SHOUGONG ${ }^{\mathrm{b}}$, Qi LIWANG ${ }^{\mathrm{b}}$, Zhang YONG $^{\mathrm{a}}$, Wang CHUNGUO $^{\mathrm{a}}$, Song WENQIN ${ }^{\mathrm{a} *}$ \\ ${ }^{\text {a }}$ Laboratory of Cell Biology, College of Life Sciences, Nankai University, Tianjin 300071, P.R. China \\ ${ }^{b}$ Laboratory of Cell Biology, The Research Institute of Forestry, The Chinese Academy of Forestry, Beijing 100091, P. R. China
}

(Received 13 June 2005; accepted 10 November 2005)

\begin{abstract}
Inter-simple sequence repeat polymorphism (ISSR) and amplified fragment length polymorphism (AFLP) analysis techniques were used in this study for the genetic fingerprinting and identification of 28 important Chinese poplar accessions. After fingerprinting, the genetic relationships among the accessions were determined. Each of three ISSR primers and four AFLP primer pairs produced fingerprint profiles that were unique to each of the accessions studied, and thus could be used solely for their identification. In general, the molecular data separated accessions from different poplar sections, and also distinguished between native and exotic accessions. In conclusion, both ISSR and AFLP could be applied to identify large numbers of poplar accessions, and could also be used to rapidly determine the genetic relationships among them. Furthermore, it is useful to conduct comparative studies with different marker systems when investigating the genetic relationships of poplar accessions.
\end{abstract}

poplar / identification / genetic relationships / AFLP / ISSR

Résumé - Identification de cultivars de peuplier chinois à l'aide de marqueurs ISSR et AFLP et étude de leur relation génétique. Des marqueurs ISSR et AFLP ont été testés dans cette étude dans un but de marquage génétique et d'identification de 28 cultivars chinois. Après leur caractérisation, l'objectif était d'étudier la relation génétique entre ces cultivars. Chacun des 3 primers ISSR et des 4 paires de primers AFLP a produit des profils qui se sont révélés uniques pour chacun des cultivars étudiés et qui peuvent être utilisés pour leur identification. Ces marqueurs ont également permis de séparer les cultivars des différentes sections de peuplier et de distinguer les cultivars autochtones et exotiques. En conclusion, les marqueurs ISSR et AFLP peuvent être utilisés pour identifier les cultivars de peuplier et également pour déterminer rapidement leur relation génétique. De plus, il semble utile de conduire des études comparatives avec plusieurs types de marqueurs pour étudier les relations génétiques entre cultivars de peuplier.

Populus / marqueurs AFLP / ISSR / identification / relation génétique

\section{INTRODUCTION}

The genus Populus L. (Salicaceae), a genus of deciduous trees, has a wide natural distribution in the Northern Hemisphere, with 29 species grouped under six separate sections [7]. The most economically important species are in the Aigeiros, Tacamahaca and Populus sections. In China, poplars are not only economically important for the architecture, lumber, and pulp and paper industries, but have also been widely used for windbreaks and erosion control. The unit of cultivation and breeding in poplars is a clone, and normally the individual cultivar is represented by a single clone. A number of poplar clones, cultivars and varieties are extensively cultivated, many of which are endemic to China [38]. Accurate identification of poplar cultivars and knowledge of their genetic relationships are essential for breeding and management strategies.

Traditionally, the process of clone and cultivar identification, registration and certification in Populus has been based on a method adopted by the International Poplar Commission. The technique is based on a combination of a total

\footnotetext{
*Corresponding author: songwq@nankai.edu.cn
}

of 64 morphological, phenological and floral characteristics [11]. However, this method of clone identification is difficult, time consuming and subjective. Since the late 1980s, several molecular marker approaches have been successfully used in a number of poplar species for the fingerprinting and identification of clones and the determination of their interrelationship. Allozyme [10,12,27] and randomly amplified polymorphic DNA (RAPD) $[5,17,31]$ analyses were initially used for this purpose because of their simplicity and relatively low cost. However, the small numbers of polymorphism present in allozyme and lack of reproducibility of RAPD limit the usefulness of these markers. Recently, the hypervariability, codominance and high reproducibility of SSR (simple sequence repeat) have led to its application for the fingerprinting and identification of poplar cultivars $[25,26]$.

Significant levels of DNA polymorphism in plants have been revealed by amplified fragment length polymorphism (AFLP) analysis [35]. It is an efficient and reliable genetic molecular marker technique that detects a much higher number of polymorphisms per reaction than that revealed by RFLP, RAPD or SSR assay $[21,23]$. Despite the fact that AFLP fragments are usually analyzed as dominant markers the technique 
Table I. List of poplar materials used in this study.

\begin{tabular}{|c|c|c|c|c|}
\hline Code & Accessions & Species & Section & Country of origin \\
\hline $\mathrm{P} 1$ & Maobaiyang-CFG37 & P. alba $\times$ P. adenopoda & Populus & China \\
\hline $\mathrm{P} 2$ & Hebeiyang-1 & P. hopeiensis & & China \\
\hline P3 & Yinbaiyang & P. alba & & China \\
\hline P4 & Yinxingyang-2 & P. alba $\times$ P. bolleana & & China \\
\hline P5 & Xingjiangyang & P. bolleana & & China \\
\hline $\mathrm{T} 1$ & Xiaoyeyang-328 & P. simonii & Tacamahaca & China \\
\hline $\mathrm{T} 2$ & Qinghaiqingyang-107 & P. cathayana & & China \\
\hline $\mathrm{T} 3$ & Wutaiqingyang-77 & P. cathayana $\times P$. simonii & & China \\
\hline $\mathrm{T} 4$ & BeiJingqingyang & P. cathayana & & China \\
\hline T5 & Maoguoyang-309 & P. trichocarpa & & Canada \\
\hline T6 & Zhongqing-10 & P. cathayana & & China \\
\hline $\mathrm{T} 7$ & Zhongqing-48 & P. cathayana & & China \\
\hline A1 & Jianadayang (Gu'an) & P. $\times$ euramericana & Aigeiros & Canada \\
\hline $\mathrm{A} 2$ & Oumeiyang-107 & P. $\times$ euramericana & & Italy \\
\hline A3 & Liaoheyang & P. deltoides & & China \\
\hline A4 & Langfang-2 & P. deltoides & & China \\
\hline A5 & Gaiyang & P. $\times$ euramericana & & China \\
\hline A6 & Liaoningyang (Fengning) & P. deltoides & & China \\
\hline A7 & Liaoningyang (Dalian) & P. deltoides & & China \\
\hline A8 & Liaoningyang (Gu'an) & P. deltoides & & China \\
\hline A9 & Jianganyang & P. nigra & & China \\
\hline A10 & Oumeiyang-13 & P. $\times$ euramericana & & Italy \\
\hline$\overline{\mathrm{TA} 1}$ & Hezuoyang & P. nigra $\times$ P. simonii & Tacamahaca $\times$ & America $\times$ China \\
\hline TA2 & Beijingyang-2 & P. nigra $\times P$. cathayana & Aigeiros & America $\times$ China \\
\hline TA3 & Zhongshang-8 & P. nigra $\times P$. cathayana & & Unkown $\times$ China \\
\hline TA4 & Mamei (Hubei) & P. deltoides $\times P$. suaveolens & & Italy $\times$ Japan \\
\hline TA5 & Qunzhongyang & P. simonii $\times P$. nigra & & America $\times$ China \\
\hline$\overline{\mathrm{TU}}$ & Huyang (Xingjiang) & P. euphratica & Turanga & China \\
\hline
\end{tabular}

has been successfully applied to many kinds of plants such as rice [18], wheat [3], vetch [22], tea [2] and larch [30]. In poplar AFLP has been used to assess genetic diversity [32], screen interspecific hybrids [6], determine the genetic structure of natural populations [1] and construct genetic linkage maps [37].

Inter-simple sequence repeat polymorphism (ISSR) analysis overcomes many of the technical limitations of RFLP and RAPD [34], and has higher reproducibility than RAPDs $[9,20]$. ISSR involves the PCR amplification of DNA using single primers composed of sequences that target abundant, rapidly evolving microsatellites throughout the eukaryotic genome $[15,16,33]$. ISSR analysis has been used to assess genetic diversity in maize [14] and beans [19], as well as to identify cultivars of potatoes [24], barley [9] and citrus [8]. Currently, there are no reports in which ISSR has been applied to fingerprinting poplar cultivars.

This study was aimed at the development of molecular marker systems for both the rapid and accurate identification of poplar accessions and the determination of genetic relationships between these accessions at the DNA level. This paper explores the potential of adopting AFLP and ISSR for high throughput fingerprinting of poplar accessions and the determination of their genetic relationships.

\section{MATERIALS AND METHODS}

\subsection{Plant materials}

Cuttings from a single ramet of each accession listed in Table I were planted in the collection of the Research Institute of Forestry at the Chinese Academy of Forestry.

\subsection{DNA extraction}

DNA was isolated using the CTAB method according to Reichardt and Rogers [28] with slight modifications. After the DNA pellet was re-dissolved in Solution IV (10 mM Tris- $\mathrm{HCl}, 0.1 \mathrm{mM}$ EDTA, 1 $\mathrm{M} \mathrm{NaCl}, \mathrm{pH} 8.0)$, it was treated with RNase A (200 ng/ $\mu \mathrm{L})$ for 60 min at $37^{\circ} \mathrm{C}$ and was extracted with 1 volume mixture of chloroform:isoamylalcohol (24:1). Finally, the high molecular weight DNA was checked for quality and quantity using agarose gel $(0.8 \%)$ electrophoresis and fluorimetry (ND-1,000 Spectrophotometer, NanoDrop).

\subsection{ISSR and AFLP analysis}

ISSR PCR reaction mixtures $(20 \mu \mathrm{L})$ contained the following components/concentrations: $10 \mathrm{mM}$ Tris- $\mathrm{HCl}$ ( $\mathrm{pH} 8.0$ ), $1.5 \mathrm{mM}$ $\mathrm{MgCl}_{2}, 0.4 \mu \mathrm{M}$ of each primer, $0.2 \mathrm{mM}$ of each dNTP (Shanghai 
Table II. Fragments and polymorphism detected by three ISSR primers and four AFLP primers pairs.

\begin{tabular}{|c|c|c|c|c|c|c|}
\hline Marker systems & Primers $^{\mathrm{a}}$ & Total fragments & $\begin{array}{l}\text { Polymorphic } \\
\text { fragments }\end{array}$ & $\begin{array}{l}\text { Percent polymorphic } \\
\text { fragments }\end{array}$ & Unique fragments & $\begin{array}{c}\text { Monomorphic } \\
\text { fragments }\end{array}$ \\
\hline \multirow[t]{5}{*}{ ISSR } & $(\mathrm{GA})_{8} \mathrm{RC}$ & 53 & 44 & $83 \%$ & 9 & 0 \\
\hline & $(\mathrm{AC})_{8} \mathrm{YA}$ & 42 & 36 & $86 \%$ & 6 & 0 \\
\hline & $(\mathrm{AG})_{8} \mathrm{YA}$ & 59 & 49 & $83 \%$ & 10 & 0 \\
\hline & Total & 154 & 129 & $84 \%$ & 25 & 0 \\
\hline & Average & 51 & 43 & $84 \%$ & 8.1 & 0 \\
\hline \multirow[t]{6}{*}{ AFLP } & & 84 & 73 & $87 \%$ & 9 & 2 \\
\hline & E-ACT $\times$ M-CAA & 78 & 62 & $79 \%$ & 11 & 5 \\
\hline & E-AAC $\times$ M-CAG & 66 & 53 & $80 \%$ & 7 & 6 \\
\hline & E-AAG $\times$ M-CAA & 77 & 64 & $83 \%$ & 12 & 1 \\
\hline & E-AAG $\times$ M-CTG & 305 & 252 & $83 \%$ & 39 & 14 \\
\hline & Total Average & 76 & 63 & $83 \%$ & 9.8 & 3.5 \\
\hline
\end{tabular}

${ }^{\mathrm{a}} \mathrm{R}=\mathrm{A}$ or $\mathrm{T}, \mathrm{Y}=\mathrm{C}$ or $\mathrm{G}$.

Sangong, China), $2.5 \%$ formamide, $30 \mathrm{ng}$ of template genomic DNA and $1 \mathrm{U}$ of Taq DNA polymerase (Toyobo, Japan). DNA amplifications were performed in a Mastercycler Gradient 5331 (Eppendorf, Germany) using the following touchdown program: $3 \mathrm{~min}$ at $94{ }^{\circ} \mathrm{C}$ for 1 cycle; $30 \mathrm{~s}$ at $94{ }^{\circ} \mathrm{C}, 60 \mathrm{~s}$ at $62{ }^{\circ} \mathrm{C}$ and $80 \mathrm{~s}$ at $72{ }^{\circ} \mathrm{C}$ for 1 cycle; annealing temperature at $62{ }^{\circ} \mathrm{C}$ was subsequently reduced by $1{ }^{\circ} \mathrm{C}$ for the next 10 cycles and remained at $52^{\circ} \mathrm{C}$ for the remaining 24 cycles; 7 min at $72{ }^{\circ} \mathrm{C}$ for 1 cycle.

The AFLP method was performed essentially according to Vos et al. [35] with minor modifications. Briefly, 100-150 ng of genomic DNA was digested with $1.5 \mathrm{U}$ of both EcoR I and Mse I (Shanghai Sangon, China). After ligation of adapters and pre-amplification, selective amplification was conducted by combining $30 \mathrm{ng}$ of both EcoR I and Mse I primers that contain three selective nucleotides.

Amplification products were separated on $4 \%$ denaturing polyacrylamide gels running at $30 \mathrm{~W}$ for $2 \mathrm{~h}$ (ISSR) or on $6 \%$ denaturing polyacrylamide gels running at $30 \mathrm{~W}$ for $1.5 \mathrm{~h}$ (AFLP) in $1 \times \mathrm{TBE}$ buffer. After silver staining [4], the gels were dried at room temperature and photographed.

In a preliminary experiment, 32 ISSR primers and 64 AFLP primer pairs were tested for selective amplification. Of these, three ISSR primers and four AFLP primer pairs that generated good patterns were selected for use in this study (Tab. II). Two independent PCR amplifications were performed using the selected ISSR primers and AFLP primer pairs, and the products were separated on independent gels. In addition, two DNA extraction replicates of a subset of samples (L5, T2, T6, A2 and A8) were conducted to assess the reproducibility of the band profiles.

\subsection{Data analysis}

Both ISSR and AFLP bands behave as dominant markers. The band profiles of each primer (primer pair) were manually scored on two occasions for the presence (1) or absence (0) of co-migrating fragments for all accessions. Only reproducible bands across two PCR amplification replicates were used in the subsequent analysis. The scored fragment sizes ranged from 200 to $1,500 \mathrm{bp}$ for ISSR and 100 to $400 \mathrm{bp}$ for AFLP. The genetic relationships among the accessions were determined by calculating the simple matching coefficient (SM). The resultant pairwise similarity matrix was employed to construct cluster plots by the unweighted pair group method with arithmetic mean (UPGMA). For each dendrogram, the cophenetic coefficient between the matrix of similarity coefficient and the matrix of cophenetic value was calculated with Mantel matrix correspondence tests. Significance of the cophenetic coefficients was determined by 5,000 permutations. Correlation coefficients between the matrices of similarity coefficients were calculated and tested as above. In addition, principal coordinate analysis (PCA) on the correlation coefficient was conducted to visualize the dispersion of the individuals in relation to the first two principal axes of variation. The NTSYS-PC software package version 2.02 [29] was used for the cluster analysis, the PCA analysis and the Mantel test. Bootstrap analysis, with 1000 re-samples, was computed using Win boot [37] to determine the confidence limits of the UPGMA dendrogram. The 0/1 matrix is available to readers upon request.

\section{RESULTS}

\subsection{Fingerprint patterns and cultivars identification}

In the current experiment, consistent results were obtained across two DNA extraction replicates for the two marker systems, with over $98 \%$ of scorable fragments reproducible for ISSR and 99\% for AFLP. Very faint fragments were not reproducible, thus such fragments were not scored in this study.

ISSR amplification from all samples resulted in multiple band fingerprint profiles (Fig. 1, Tab. II). Each of the three primers produced fingerprint profiles unique to the accessions studied. Therefore, it was possible to distinguish between all of the accessions. The average number of scorable fragments per primer was 51, with a range from $42\left[(\mathrm{AC})_{8} \mathrm{SA}\right]$ to 59 $\left[(\mathrm{AG})_{8} \mathrm{SA}\right]$, and the average number of polymorphic fragments per primer was 43, with a range from 36 [(AC) $)_{8} \mathrm{SA}$ ] to 49 $\left[(\mathrm{AG})_{8} \mathrm{SA}\right]$. Of the total 154 scorable fragments, $129(84 \%)$ were polymorphic among the accessions, and 25 were unique to 11 of the studied cultivars (data not shown). 


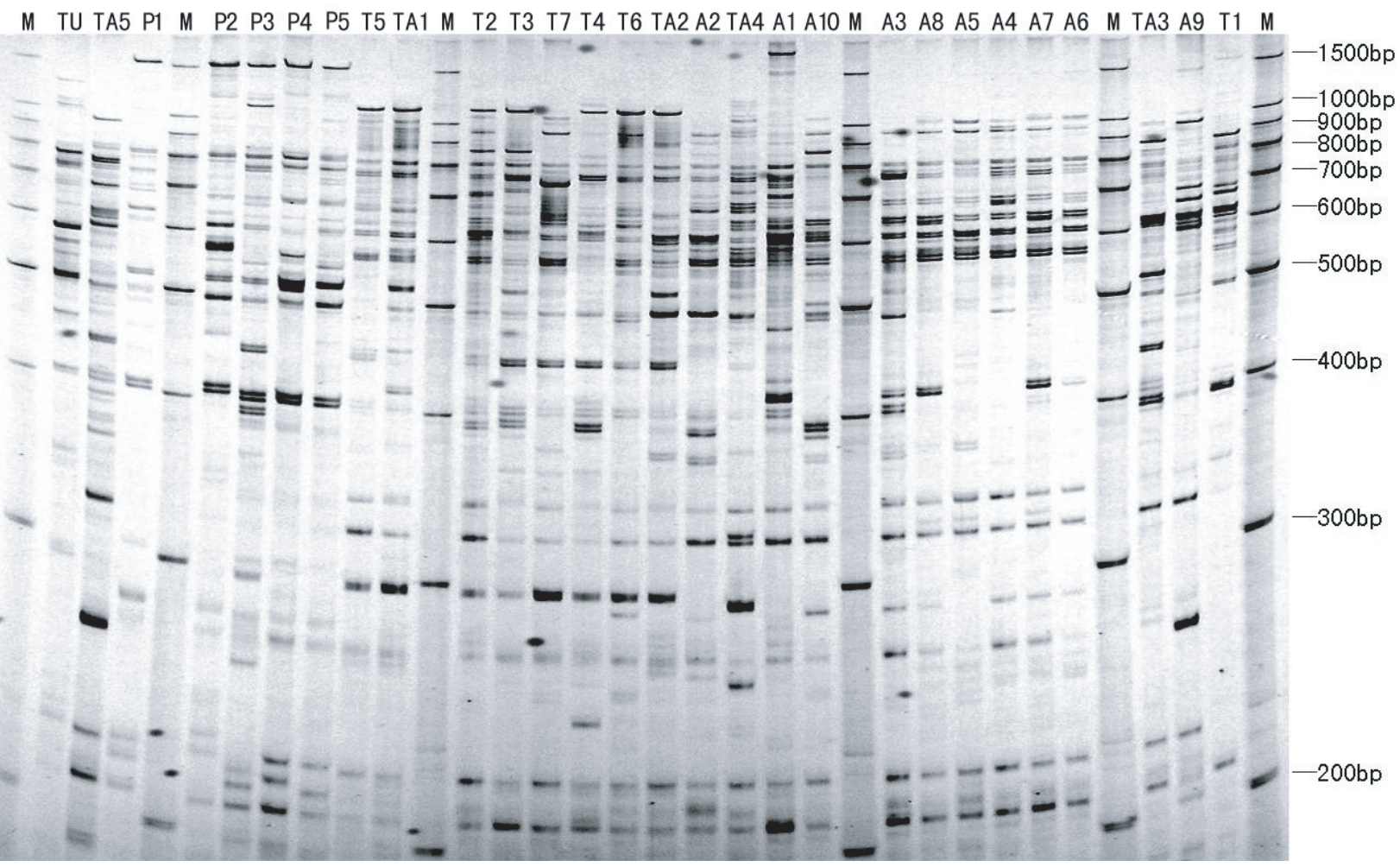

Figure 1. ISSR fingerprint pattern generated using primer $(\mathrm{GA})_{8} \mathrm{RC}$.

Similarly, the accessions studied could be uniquely fingerprinted and differentiated by each of four AFLP primer pairs (Fig. 2, Tab. II). The average number of scorable fragments per primer was 76 , with a range from 66 (E-AAG $\times$ M-CAA) to 84 (E-ACT $\times$ M-CAA), while the average number of polymorphic fragments per primer was 63, with a range from 53 (EAAG $\times$ M-CAA) to 73 (E-ACT $\times$ M-CAA). Of the 305 scorable AFLP fragments, $252(83 \%)$ were polymorphic among the accessions, 14 were monomorphic among the accessions, and 39 fragments were unique to 15 of the cultivars studied (data not shown).

\subsection{Inter-cultivars genetic relationships}

The Mantel test of the correlation coefficient between the two similarity matrices (data not shown) based on ISSR and AFLP showed a high value with $r=0.84(P<0.0004$, Good fit). The similarity coefficients for the 378 possible pairs of 28 poplar accessions ranged from 0.513 to 0.961 for ISSR and from 0.440 to 0.944 for AFLP. Accessions belonging to Populus and cultivars belonging to Tacamahaca, Aigeiros and Tacamahaca $\times$ Aigeiros shared very low genetic similarity with coefficients ranging from 0.513 to 0.695 for ISSR and from 0.440 to 0.635 for AFLP.

The dendrograms (Fig. 3) based on the two marker systems were truly representative of their similarity matrices since the cophenetic correlation values were $0.875(P<0.0004$, Good fit) for ISSR and $0.946(P<0.0004$, Very good fit $)$ for AFLP.
However, they were not indicative of grouping according to poplar sections, because the bootstrap values of some of clusters were lower than $50 \%$. However, accessions from Populus were always in the same cluster while accessions from Populus deltoides clustered together. An overview of the genetic similarities between poplar sections may be obtained by PCA analysis. The results of the two PCA plots (Fig. 4) were generally consistent, each dividing the 28 accessions into five major groups: All Populus accessions were grouped into cluster I and all those accessions from Populus deltoides formed cluster III. The only accession from the Turanga section, P. euphratica, was the sole member of cluster II. Most of the accessions with exotic origins were from Tacamahaca, Aigeiros or Tacamahaca $\times$ Aigeiros, and grouped in cluster IV, while cluster V included most of accessions native to China from Tacamahaca, Aigeiros or Tacamahaca $\times$ Aigeiros.

\section{DISCUSSION}

The results of this work clearly demonstrate that both AFLP and ISSR markers can be used for the identification of poplar accessions. In fact, all of the analysed accessions were uniquely identified both by their AFLP fingerprints and by their ISSR profiles. It is worth noting that each accession produced its own unique AFLP and ISSR fingerprinting profile using any one of the ISSR and AFLP primers. Therefore, any of the primers could be used separately to identify these cultivars in the future. 


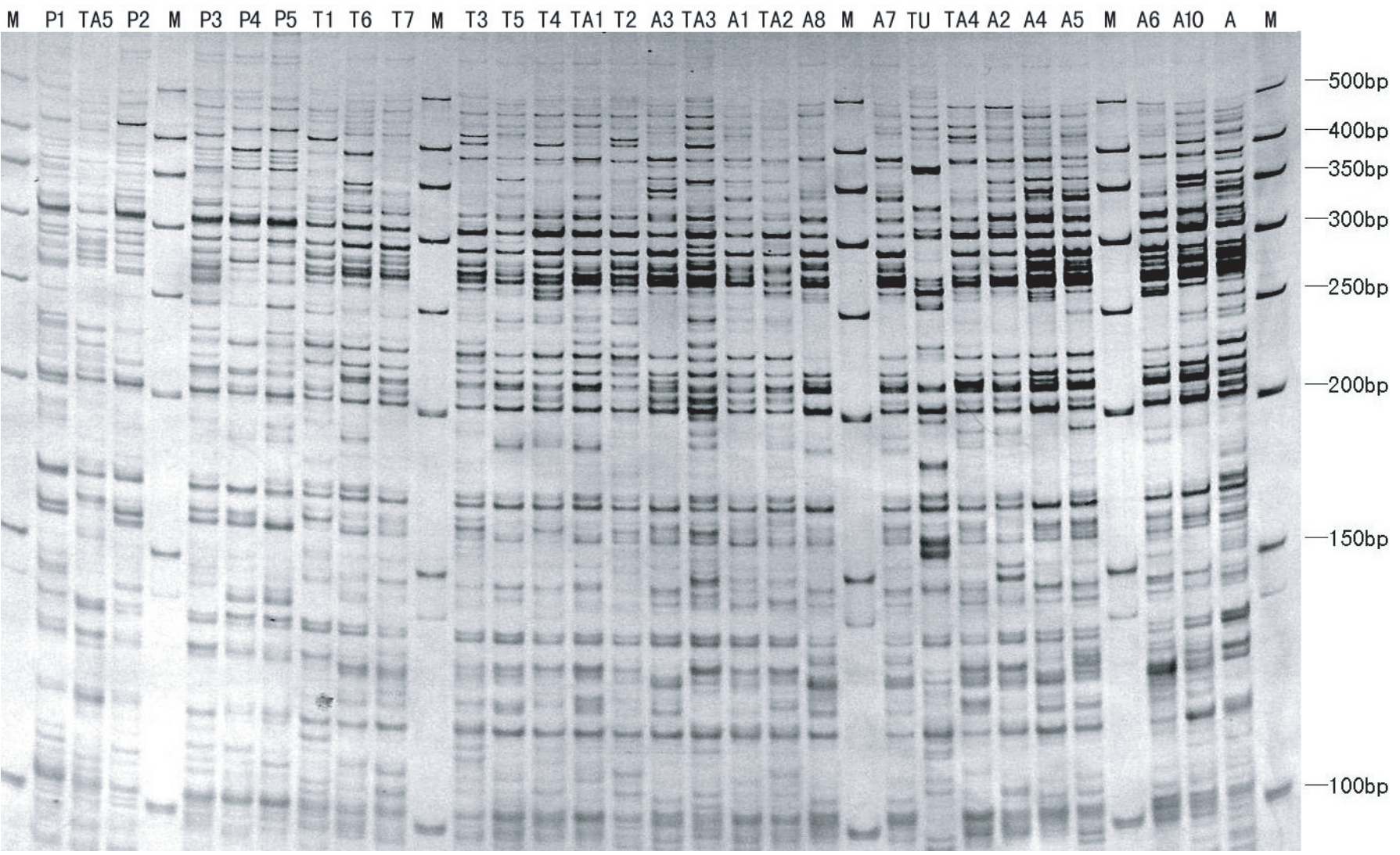

Figure 2. AFLP fingerprint pattern generated using primer pair E-AAG $\times$ M-CAA.

In addition to providing the facility to identify individual accessions, the ISSR markers and AFLP markers also tended to reveal those accessions that were closely related. For example, our data showed that A4, A6, A7 and A8 were closely related. In fact, this was accordant with their origin. A6, A7 and $\mathrm{A} 8$ belong to the cultivar "Liaoningyang" which is the product of a cross between "I-69 (Populus deltoides Bartr. cv. 'Lux' ex I-69/55) and Populus deltoides cv. Shanhaiguanensis". This cultivar consists of 6 clones that are difficult to discriminate morphologically [39]. In addition, A4, although not the same cultivar, originated from the same cross as "Liaoningyang" [39]. In the cluster plots, these four accessions were grouped into a cluster with a higher similarity level.

The two PCA plots (Fig. 4), to some extent, showed a separation of cultivars among different sections of the poplar, and differentiated between accessions that were native to China and those of exotic origin. However, the PCA plots and the cluster plots grouped the accessions from Tacamahaca with those from Aigeiros; and groups IV and V each included accessions from Tacamahaca, Aigeiros or Tacamahaca $\times$ Aigeiros. The molecular data may also highlight incorrect identifications. For example, T6 and T7 were identified as members of Populus cathayana in the Tacamahaca section which originated in China. However, these did not group into a single cluster with the other accessions of this species that had their origin in China (T2, T3 and T4). Instead, they were placed in a cluster in which most of the accessions (A1, A2, A10, T5 and TA4) are of exotic origin. Thus, the identities or the origins of these two accessions of Populus cathayana are questionable. Further experiments are needed to clarify these issues with additional ISSR primers or AFLP primer pairs or through other methods.

The data also indicate that AFLP is more effective than ISSR since, on average, more polymorphic fragments could be obtained from an AFLP primer pair than from an ISSR primer (43 for ISSR and 63 for AFLP). However, ISSR has the distinct advantage of offering a simpler methodology and is thereby easier to implement than AFLP. Both marker systems provided broadly similar results in determining the genetic relationships of poplar accessions. However, the fact that some differences existed between corresponding clusters in the two PCA plots and the two dendrograms indicates that it is useful to conduct comparative studies of the different marker systems when determining the genetic relationships of poplar cultivars. The differences could be partially explained by the different number of PCR fragments analyzed (129 for ISSR and 252 for AFLP). This possibility reinforces the importance of the number of fragments and their coverage of the overall genome. Alternatively, it could be that the two marker systems target different genomic DNA sequences that exhibit slightly different levels of variation. 

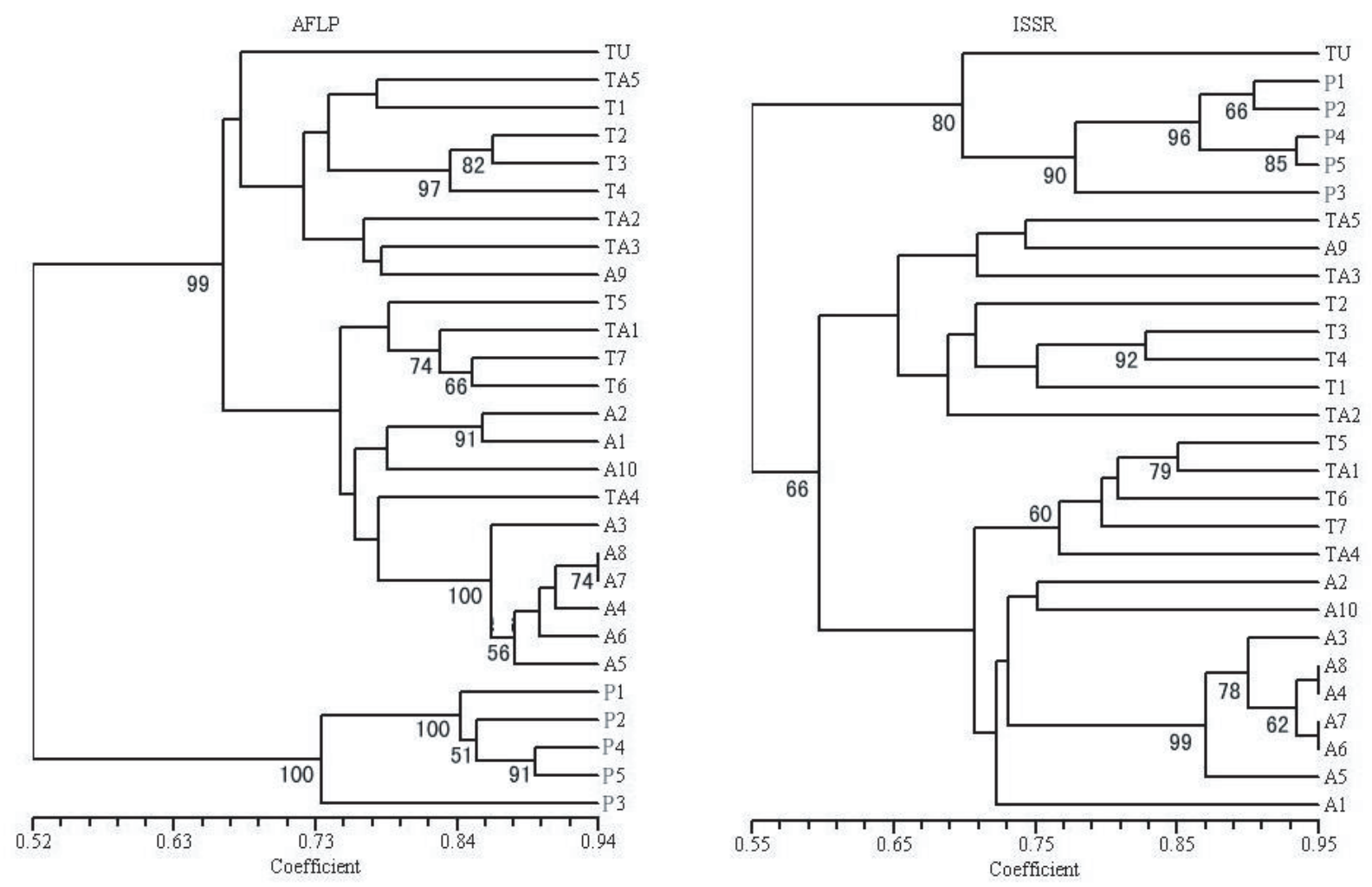

Figure 3. UPGMA dendrogram using ISSR and AFLP. The numbers at the forks indicate the confidence limits for the grouping of those accessions, which are to the right of that fork. Only bootstrap values greater than $50 \%$ are reported.
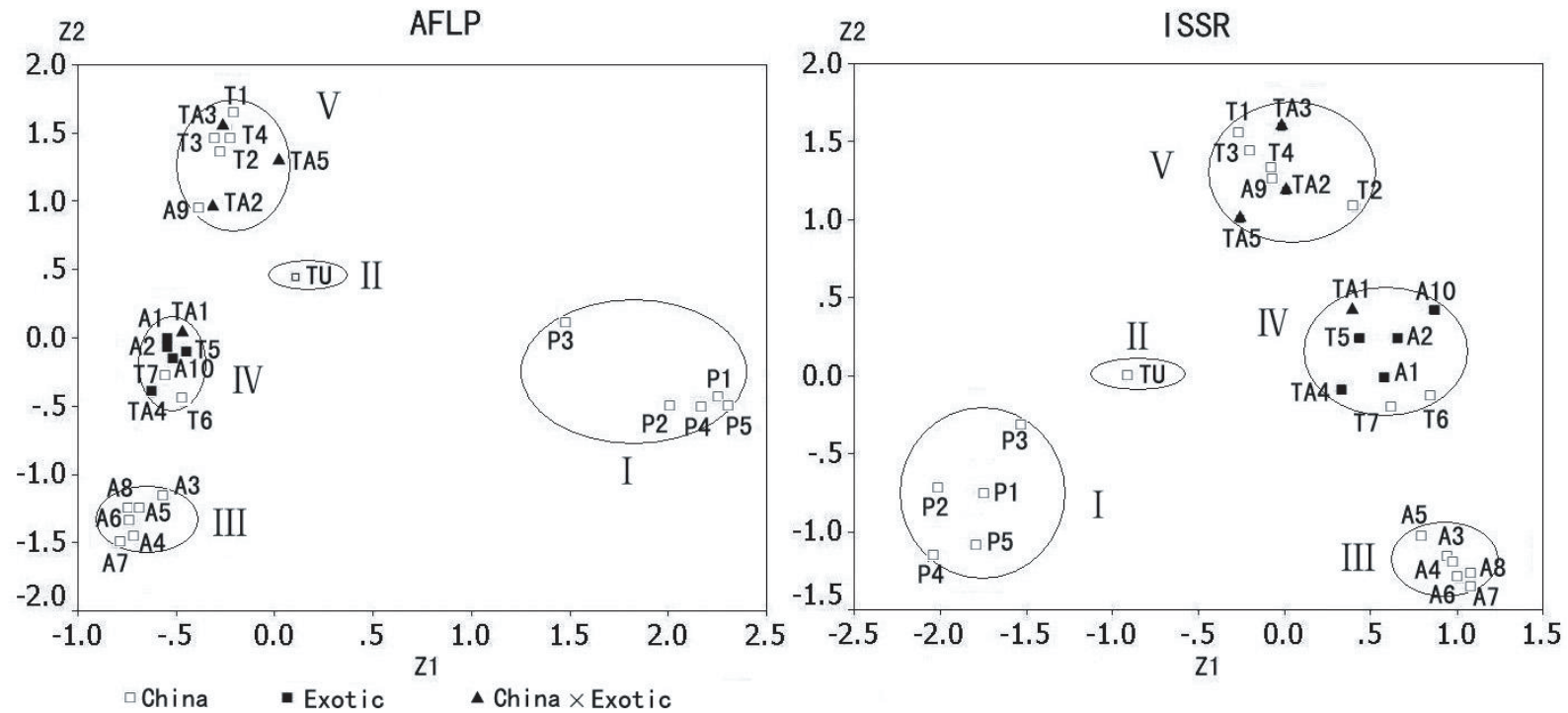

Figure 4. Principal coordinate analysis (PCA) using ISSR and AFLP. Variation explained by the first principal component (Z1) is $22 \%$ for ISSR and $26 \%$ for AFLP, and is $17 \%$ for ISSR and 13\% for AFLP for the second principal component (Z2). 
As with other DNA molecular techniques, such as RFLP, RAPD and SSR, an obvious advantage of AFLP and ISSR over traditional, morphologically based methods is that there is an immense number of markers that can be generated rapidly and are not affected by environmental factors. In fact, molecular techniques vary in the way that they resolve genetic differences, in the type of data they generate and in the taxonomic levels at which they can be most appropriately applied. The AFLP and ISSR analysis techniques can detect much higher numbers of polymorphisms per reaction than RFLP, RAPD and SSR assays. Moreover, the results of this study show that fingerprinting profiles based on ISSR and AFLP can be highly replicable in the same laboratory. Indeed Jones et al. showed that the between-laboratory error for AFLP markers was less than $0.6 \%$ [13], indicating that AFLP can also be highly replicable across laboratories. Thus, AFLP or ISSR markers could prove very useful for the rapid and accurate identification of large numbers of poplar accessions and for the determination of their genetic relationships. Although it is sometimes more difficult to compare from lab to lab and process band data for these two methods than for SSR, if the appropriate reference samples are used to standardize band scoring across laboratories, the problems will be possibly solved.

It is essential for future breeding programs that the genetic diversity and genetic relationships of the native and exotic germplasm resources in poplar be determined using a variety of molecular markers. In particular, the poplar seedling industry requires a reliable means of cultivar identification that can be applied routinely to large numbers of samples. The present work has demonstrated that ISSR and AFLP could be used for these purposes.

Acknowledgements: The authors are very grateful to the reviewers for comments on the manuscript, Ms. Dunlian Qiu from Sichuan Academy of Agricultural Sciences of China for helpful suggestions on the manuscript, the following people for their assistance in obtaining poplar materials: Yuquan Zhou and Jianzhong Ren from Datong in Shanxi province, Zhangshui Chen from Shunyi and Huairou in Beijing Drs. This study was supported by grants from National "948" Program (No. 98-4-04-02) and National Key Basic Research Program ("973") (G19990160) - "Molecular Research on Trees Improvement".

\section{REFERENCES}

[1] Arens P., Coops H., Jansen J., Vosman B., Molecular genetic analysis of black poplar (Populus nigra L.) along Dutch rivers, Mol. Ecol. 7 (1998) 11-18.

[2] Balasaravanan T., Pius P.K., Raj Kumar R., Muraleedharan N., Shasany A.K., Genetic diversity among south Indian tea germplasm (Camelliasinensis, C. assamica and C. assamica spp. lasiocalyx) using AFLP markers, Plant Sci. 165 (2003) 365-372.

[3] Barrett B.A., Kidwell K.K., AFLP-based genetic diversity assessment among wheat cultivars from the Pacific North-west, Crop Sci. 38 (1998) 1261-1271.

[4] Bassam B.J., Caetano-Anolles G., Gresshoff P.M., Fast and sensitive silver staining of DNA in polyacrylamide gels, Anal. Biochem. 196 (1991) 80-83.

[5] Castiglione S., Wang G., Damiani G., Bandi C., Bisoffi S., Sala F., RAPD fingerprints for identification and taxonomic studies of elite poplar (Populus spp.) clones, Theor. Appl. Genet. 87 (1993) 54-59.
[6] Chauhan N., Negi M.S., Sabharwal V., Khurana D.K., Lakshmikumaran M., Screening interspecific hybrids of Populus (P. ciliata $\times$ maximowiczii) using AFLP markers, Theor. Appl. Genet. 108 (2004) 951-957.

[7] Eckenwalder J.E., Systematics, evolution of Populus. In: Stettler R.F., Bradshaw H.D. Jr., Heilman P.E., Hinckley T.M. (Eds.), Biology of Populus and its implications for management and conservation, Ottawa, NRC Research Press, 1996, pp. 7-32.

[8] Fang D.Q., Roose M.L., Identification of closely related citrus cultivars with inter-simple sequence repeat markers, Theor. Appl. Genet. 95 (1997) 408-417.

[9] Fernández M.E., Figueiras A.M., Benito C., The use of ISSR and RAPD markers for detecting DNA polymorphism, genotype identification and genetic diversity among barley cultivars with known origin, Theor. Appl. Genet. 104 (2002) 845-851.

[10] Heinze B., PCR-based chloroplast DNA assay for the identification of native Populus nigra and introduced poplar hybrids in Europe, For. Genet. 5 (1998) 31-38.

[11] IUPOV, Guidelines for the conduct of tests for distinctness, homogeneity and stability Populus L., International Union for the Protection of New Varieties of Plants, Geneva, Switzerland, 1981.

[12] Janssen A., Unterscheidung der beiden Schwarzpappelarten Populus nigra L. und $P$. deltoides Marsh. sowie ihrer Arthybride $P . \times$ euramericana (Dode) Guinier mit Hilfe von Isoenzymmmustern, Holzzucht 51 (1997) 17-23.

[13] Jones C.J., Edwards K.J., Castaglione S., Winfield M.O., Sala F., van de Wiel C., Bredemeijer G., Vosman B., Matthes M., Daly A., Brettschneider R., Bettini P., Buiatti M., Maestri E., Malcevschi A., Marmiroli N., Aert R., Volckaert G., Rueda J., Linacero R., Vazquez A., Karp A., Reproducibility testing of RAPD, AFLP and SSR markers in plants by a network of European laboratories, Mol. Breed. 3 (1997) 381-390,

[14] Kantety R.V., Zeng X.P., Bennetzen J.L., Zehr B.E., Assessment of genetic diversity in dent and popcorn (Zea mays L.) inbred lines using inter-simple sequence repeat (ISSR) amplification, Mol. Breed. 1 (1995) 365-373.

[15] Kijas J.M.H., Fowler J.C.S., Thomas M.R., An evaluation of sequence tagged microsatellite site markers for genetic analysis within Citrus and related species, Genome 38 (1995) 349-355.

[16] Levinson G., Gutman G.A., Slipped-strand mispairing: a major mechanism for DNA sequence evolution, Mol. Biol. Evol. 4 (1987) 203-221.

[17] Lin D., Hubbes M., Zsuffa L., Differentiation of poplar and willow clones using RAPD fingerprints, Tree Physiol. 14 (1994) $1097-$ 1105.

[18] Mackill D.J., Zhang Z., Redona E.D., Colowit P.M., Level of polymorphism and genetic mapping of AFLP markers in rice, Genome 39 (1996) 969-977.

[19] Métais I., Aubry C., Hamon B., Jalouzot R., Description and analysis of genetic diversity between commercial bean lines (Phaseolus vulgaris L.), Theor. Appl. Genet. 101 (2000) 1207-1214.

[20] Meyer W., Mitchell T.G., Freedman E.Z., Vilgalys R., Hybridization probes for conventional DNA fingerprinting used as single primers in the polymerase chain reaction to distinguish strains of Cryptococcus neoformans, J. Clin. Microbiol. 31 (1993) 2274-2280.

[21] Pejic I., Ajmone-Marsan P., Morgante M., Kozumplick V., Castiglioni P., Taramino G., Motto M., Comparative analysis of genetic similarity among Maize in bred lines detected by RFLPs, RAPDs, SSRs, and AFLPs, Theor. Appl. Genet. 97 (1998) 12481255.

[22] Potokina E., Blattner F.R., Alexandrova T., Bachmann K., AFLP diversity in the common vetch (Vicia sativa $\mathrm{L}$.) on the world scale, Theor. Appl. Genet. 105 (2002) 58-67.

[23] Powell W., Morgante M., Andre C., The comparison of RFLP, RAPD, AFLP and SSR (microsatellite) markers for germplasm analysis, Mol. Breed. 2 (1996) 225-238. 
[24] Prevost A., Wilkinson M.J., A new system of comparing PCR primers applied to ISSR fingerprinting of potato cultivars, Theor. Appl. Genet. 98 (1999) 107-112.

[25] Rahman M.H., Rajora O.P., Microsatellite DNA fingerprinting, differentiation, and genetic relationships of clones, cultivars, and varieties of six poplar species from three sections of the genus Populus, Genome 45 (2002) 1083-1094.

[26] Rajora O.P., Rahman M.H., Microsatellite DNA and RAPD fingerprinting, identification and genetic relationships of hybrid poplar (Populus $\times$ canadensis) cultivars, Theor. Appl. Genet. 106 (2003) 470-477.

[27] Rajora O.P., Characterization of 43 Populus nigra L. clones representing selections, cultivars and botanical varieties based on their multilocus allozyme genotypes, Euphytica 43 (1989) 197-206.

[28] Reichardt M.J., Rogers S.J., Plant DNA isolation using CTAB, In: Ausubel F.M., Brent R., Kingston R.E., Moore D.D., Seidman J.G., Smith J.A., Struhl K. (Eds.), Current protocols in molecular biology, USA, John Wiley and Sons, Suppl. 22, 1993.

[29] Rohlf F.J., NTSYS-PC numerical taxonomy and multivariate analysis system, version 2.02, Exeter Software, New York, 1998.

[30] Semerikov Vladimir L., Hengqing Z., Lascoux S.M.M., Conflicting phylogenies of Larix (Pinaceae) based on cytoplasmic and nuclear DNA, Mol. Phylogenet. Evol. 27 (2003) 173-184.

[31] Sigurdsson V., Anamthawat-Jonsson K., Sigurgeirsson A., DNA fingerprinting of Populus trichocarpa clones using RAPD markers, New For. 10 (1995) 197-206.

[32] Storme V., Vanden Broeck A., Ivens B., Halfmaerten D., Van Slycken J., Castiglione S., Grassi F., Fossati T., Cottrell J.E., Tabbener H.E., Lef vre F., Saintagne C., Fluch S., Krystufek V., Burg K., Bord cs S., Borovic A., Gebhardt K., Vornam B., Pohl A.,
Alba N., Agndez D., Maestro C., Notivol E., Bovenschen J., van Dam B.C., van der Schoot J., Vosman B., Boerjan W., Smulders M.J.M., Ex-situ conservation of Black poplar in Europe: genetic diversity in nine gene bank collections and their value for nature development, Theor. Appl. Genet. 108 (2004) 969 -981.

[33] Tautz D., Renz M., Simple sequences are ubiquitous repetitive components of eukaryotic genomes, Nucleic Acids Res. 12 (1984) $4127-4138$.

[34] Tsumura Y., Ohba K., Strauss S.H., Diversity, inheritance of inter-simple sequence repeat polymorphisms in Douglas-fir (Pseudotsuga menziesii) and sugi (Cryptomeria japonica), Theor. Appl. Genet. 92 (1996) 40-45.

[35] Vos P., Hogers R., Bleeker M., Reijans M., Lee T., Hornes M., Frijters A., Pot J., Peleman J., Kupier M., Zabeau M., AFLP: A new technique for DNA fingerprinting, Nucleic Acids Res. 23 (1995) 4407-4414.

[36] Yap I.V., Nelson R.J., WINBOOT a program for performing bootstrap analysis of binary data to determine the confidence limits of UPGMA-based dendrograms, IRRI Disc. Pap. Ser. 14, International Rice Research Institute, Manila, Philippines, 1996.

[37] Zhang D., Zhang Z., Yang K., Li B., Genetic mapping in (Populus tomentosa $\times$ Populus bolleana) and Populus tomentosa Carr. using AFLP markers, Theor. Appl. Genet. 108 (2004) 657 -662.

[38] Zhao Tianxi, Chen Zhangshui, The poplar intensive cultivation in China. Beijing, China Science Technology Press, 1994, pp. 9-13.

[39] Zheng Shikai, Li Yumin, Lu Xinzheng, Introduction to poplar varieties (IV), Pract. For. Technol. 2 (2003) 12-13. 